\title{
Negative cancer beliefs, recognition of cancer symptoms and anticipated time to help-seeking: an international cancer benchmarking partnership (ICBP) study
}

Anette Fischer Pedersen ${ }^{1 *}$, Lindsay Forbes ${ }^{2}$, Kate Brain ${ }^{3}$, Line Hvidberg ${ }^{1}$, Christian Nielsen Wulff4, Magdalena Lagerlund ${ }^{5}$, Senada Hajdarevic ${ }^{6}$, Samantha L. Quaife ${ }^{7}$ and Peter Vedsted ${ }^{1}$

\begin{abstract}
Background: Understanding what influences people to seek help can inform interventions to promote earlier diagnosis of cancer, and ultimately better cancer survival. We aimed to examine relationships between negative cancer beliefs, recognition of cancer symptoms and how long people think they would take to go to the doctor with possible cancer symptoms (anticipated patient intervals).

Methods: Telephone interviews of 20,814 individuals (50+) in the United Kingdom, Australia, Canada, Denmark, Norway and Sweden were carried out using the Awareness and Beliefs about Cancer Measure (ABC). ABC included items on cancer beliefs, recognition of cancer symptoms and anticipated time to help-seeking for cough and rectal bleeding. The anticipated time to help-seeking was dichotomised as over one month for persistent cough and over one week for rectal bleeding.

Results: Not recognising persistent cough/hoarseness and unexplained bleeding as cancer symptoms increased the likelihood of a longer anticipated patient interval for persistent cough $(\mathrm{OR}=1.66 ; 95 \% \mathrm{Cl}=1.47-1.87)$ and rectal bleeding $(\mathrm{OR}=1.90 ; 95 \% \mathrm{Cl}=1.58-2.30)$, respectively. Endorsing four or more out of six negative beliefs about cancer increased the likelihood of longer anticipated patient intervals for persistent cough and rectal bleeding (OR $=2.18 ; 95 \% \mathrm{Cl}=1.71-2.78$ and $\mathrm{OR}=1.97 ; 95 \% \mathrm{Cl}=1.51-2.57)$. Many negative beliefs about cancer moderated the relationship between not recognising unexplained bleeding as a cancer symptom and longer anticipated patient interval for rectal bleeding $(p=0.005)$.
\end{abstract}

Conclusions: Intervention studies should address both negative beliefs about cancer and knowledge of symptoms to optimise the effect.

Keywords: Behavioural medicine, Primary health care, Surveys and questionnaires, Telephone

\section{Background}

Diagnosis of cancer at an early stage is important to optimise the outcomes of cancer [1]. A study of more than 2000 patients with 15 different cancers showed that $21 \%$ had delayed symptomatic presentation for more than three months [2]. Therefore, improvement of our

\footnotetext{
* Correspondence: afp@ph.au.dk

${ }^{1}$ Research Unit for General Practice and Research Centre for Cancer Diagnosis in Primary Care (CaP), Aarhus University, Bartholins Allé 2, 8000 Aarhus C, Denmark

Full list of author information is available at the end of the article
}

understanding of individuals' decision to seek medical help for symptoms that could be a sign of cancer is very important.

The patient interval is defined as the time period between an individual's first discovery of a change in the body and the first consultation with a healthcare professional, often the general practitioner [1]. Cognitive factors such as knowledge about disease and symptoms seem to play a role in decision-making about healthcare seeking [3-5]. For instance, cancer patients who did not perceive their initial symptoms as serious were twice as 
likely to postpone help-seeking for at least three months [2]. Nevertheless, there is often a gap between knowledge and behaviour, with knowledge about cancer symptoms not entirely predictive of help-seeking behaviour [6, 7]. The relationship between negative cancer beliefs (NCBs) and help-seeking for a symptom which may be a sign of cancer has been under-researched.

The aim of this paper was to explore the influence of NCBs on the likelihood of long anticipated patient intervals for persistent cough and rectal bleeding. Persistent cough and rectal bleeding may be signs of lung cancer and colorectal cancer, respectively, and these two cancers strike both men and women. They are two of the most common cancers, yet their symptoms may be perceived as less alarming or less specific to cancer than "classic" symptoms such as a lump. First, we examined the association between NCBs about cancer and longer anticipated patient intervals for persistent cough and rectal bleeding while adjusting for symptom recognition (see Fig. 1a). Second, we examined whether NCBs about cancer have a moderating influence on the association between not recognising persistent cough/hoarseness or unexplained bleeding as possible signs of cancer and a long anticipated patient interval for persistent cough and rectal bleeding, respectively (see Fig. 1b).

\section{Methods}

Data were used from a survey conducted as part of the International Cancer Benchmarking Partnership (ICBP) which was initiated to study international variation in cancer survival. Module 2 of the ICBP measured population awareness and beliefs about cancer [8]. Data were collected from May to September 2011 [9] in six countries: the United Kingdom (England, Wales and Northern Ireland), Australia (New South Wales and Victoria), Canada, Denmark, Norway and Sweden.

Computer-assisted telephone interviews were carried out by the research market company Ipsos MORI. All men and women aged 50 years or more living in private households and able to understand the official language of the country were eligible. The researchers aimed to achieve a sample size of 2000 respondents in each country or jurisdiction, and a total of 20,814 respondents participated. Data collection and response rates have been described in detail elsewhere [9-11].

NCBs, recognition of cancer symptoms and anticipated help-seeking were assessed by the internationally developed and validated Awareness and Beliefs about Cancer Measure (ABC) [12].

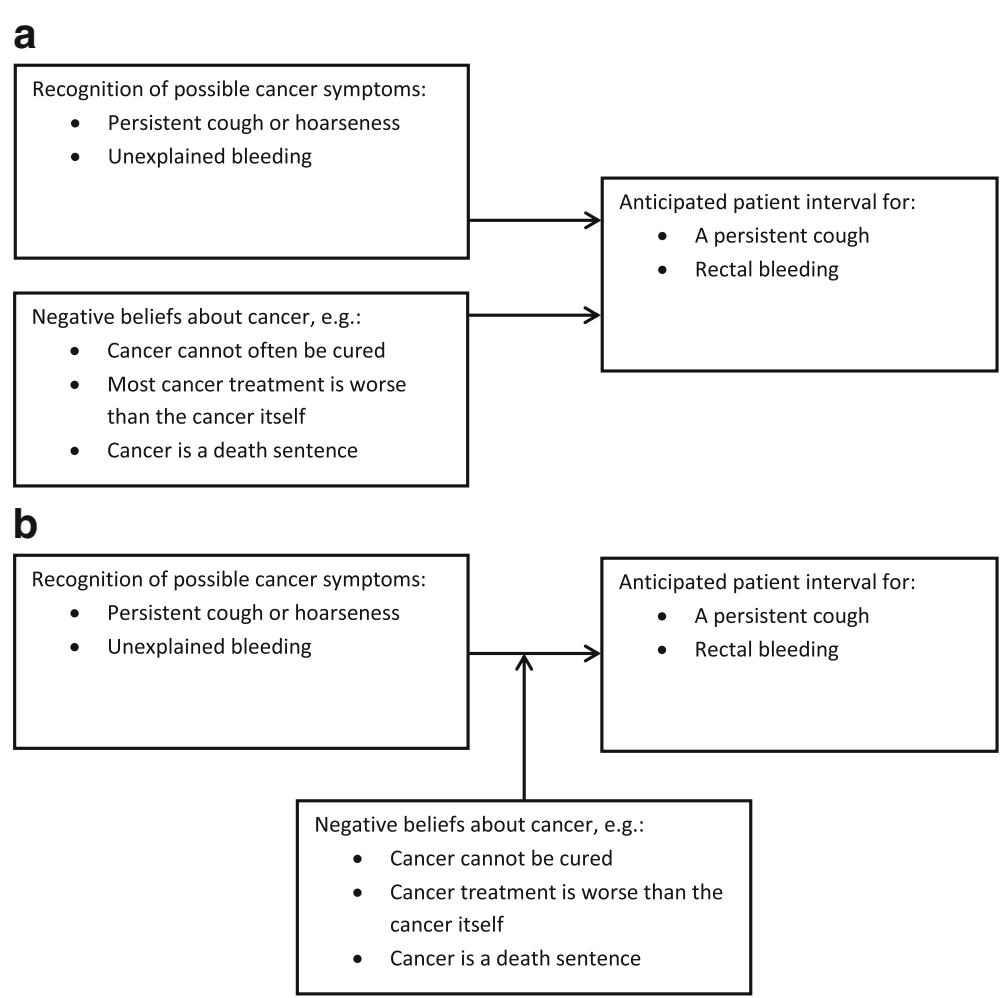

Fig. 1 Models of negative cancer beliefs as either independent variable or effect moderator. a Independent effects of negative beliefs about cancer and recognition of cancer symptoms on anticipated patient intervals. $\mathbf{b}$ Negative beliefs about cancer as an effect moderator of the association between recognition of cancer symptoms and length of the anticipated patient interval 
Dependent variable: anticipated time to help-seeking for persistent cough and rectal bleeding

Four items from the $\mathrm{ABC}$ assessed the anticipated patient interval for symptoms that could be signs of cancer. In the present study, lung cancer and colorectal cancer were the two target cancers and the anticipated patient intervals for these two cancers were assessed by asking the respondents how long they would wait before seeking help after experiencing a persistent cough and rectal bleeding, respectively. No standardised and internationally accepted guidelines are available about when to seek help for these symptoms. As presented in Table 1, anticipated patient intervals of more than one month for persistent cough and of more than one week for rectal bleeding were categorised as "long". These cut-offs were chosen for two reasons. First they ensured that we had enough subjects in our "long" and "short" patient interval categories. Second, cut-offs appeared reasonable as everyone experiences a cough now and then and the duration of the symptom plays an important role when determining whether the cough needs medical attention. On the contrary, rectal bleeding happening more than once should always cause concern.

\section{Independent variable: recognition of persistent cough or hoarseness and unexplained bleeding as cancer symptoms}

The ABC included 11 possible cancer symptoms and respondents were asked to determine whether they thought that each symptom could be a warning sign of cancer. The warning signs most closely related to the two target cancers were persistent cough or hoarseness and unexplained bleeding. Response options and coding are shown in Table 1.

\section{Independent variable and hypothesised moderator: negative cancer beliefs (NCBs)}

Six statements examined respondents' beliefs about cancer. The wording, response options and coding are shown in Table 1. The number of NCBs endorsed was summed for each respondent. As the proportion of respondents declaring five or six NCBs was limited (0.5\%), the survey data from these respondents were grouped with the survey data from respondents declaring four NCBs to ensure sufficient statistical power.

\section{Demographic characteristics}

Data were collected on sex, age (categorised as 50 to 59 years, 60 to 69 years, 70 to 79 years and 80 years or older), marital status (categorised as married/cohabiting vs. single/divorced/separated/widowed), highest level of education (categorised as no university degree vs. university degree), experience of cancer themselves and/or in family/friend (categorised as yes/no), country and smoking status (categorised as never/former vs. current). Smokers have been shown to declare more NCBs than non-smokers [13].

\section{Statistics}

The associations between non-recognition of persistent cough or hoarseness and unexplained bleeding as cancer symptoms, number of NCBs about cancer and long anticipated patient intervals for persistent cough and rectal bleeding, respectively, were examined in two separate logistic regression analyses. Odds ratios (ORs) were calculated as measures of association. In the adjusted analyses, both non-recognition of symptom and number of NCBs were included as independent variables and sex, age, marital status, highest level of education, smoking status, experience of cancer and country were included as co-variables. As a sensitivity analysis, the logistic regression analyses were repeated with the answer "don't know" to the questions about whether persistent cough or hoarseness and unexplained bleeding could be signs of cancer coded as "non-recognition" instead of missing. To test for a moderating effect of NCBs on the association between non-recognition of the symptoms and length of anticipated patient intervals, two interaction terms were computed: non-recognition of persistent cough or hoarseness as a cancer symptom multiplied with the number of NCBs and nonrecognition of unexplained bleeding as a cancer symptom multiplied with the number of NCBs. These two interaction terms were included in two separate logistic regression analyses which also included independent and demographic variables. The likelihood-ratio (LR) test was used to determine whether the models with and without the interaction terms were statistically significantly different. In case of a statistically significant interaction, predictive margins would be used to visualise the effect and to assist interpretation (https://www.cscu.cornell.edu/news/statnews/stnews84.pdf). $P$-values of $5 \%$ or less were considered statistically significant. Data were analysed using STATA 13.1.

\section{Results}

Demographic characteristics and proportion of respondents with none to four or more NCBs are shown in Table 2 (see additional file 1 for these results reported for each country).

Not recognising persistent cough or hoarseness as a possible sign of cancer $(\mathrm{OR}=1.66,95 \% \mathrm{CI}=1.47-1$. $87)$ and a high number of $\mathrm{NCBs}\left(\mathrm{OR}_{\geq 4} \mathrm{NCBs}=2.18\right.$, 95\% CI $=1.71-2.78)$ were independently associated with an increased likelihood of a longer anticipated patient interval for persistent cough (Table 3). Not recognising unexplained bleeding as a possible sign of cancer $(\mathrm{OR}=1.90,95 \% \mathrm{CI}=1.58-2.30)$ and a high 
Table 1 Responses to questions about anticipated patient intervals and symptom awareness and how they were classified

\begin{tabular}{|c|c|c|c|c|}
\hline \multicolumn{5}{|c|}{ Dependent variables: Anticipated patient intervals } \\
\hline & \multicolumn{2}{|c|}{$\begin{array}{c}\text { How long would it take you to go to the } \\
\text { doctor from the first time you noticed a } \\
\text { persistent cough? }\end{array}$} & \multicolumn{2}{|c|}{$\begin{array}{l}\text { How long would it take you to go to the doctor } \\
\text { from the first time you noticed rectal bleeding? }\end{array}$} \\
\hline Response categories: & N (\%) & Classification & N (\%) & Classification \\
\hline I would go as soon as I noticed & $2669(12.8)$ & Short pt. interval & $12,617(60.6)$ & Short pt. interval \\
\hline Up to 1 week & $3750(18.0)$ & Short pt. interval & $5017(24.1)$ & Short pt. interval \\
\hline Over 1 up to 2 weeks & 4029 (19.4) & Short pt. interval & $1323(6.4)$ & Long pt. interval \\
\hline Over 2 up to 3 weeks & $3001(14.4)$ & Short pt. interval & $518(2.5)$ & Long pt. interval \\
\hline Over 3 up to 4 weeks & $2557(12.3)$ & Short pt. interval & $357(1.7)$ & Long pt. interval \\
\hline More than a month & $3267(15.7)$ & Long pt. interval & $488(2.3)$ & Long pt. interval \\
\hline I would not contact a/my doctor & $844(4.1)$ & Long pt. interval & $171(0.8)$ & Long pt. interval \\
\hline I would go to another HCP & $320(1.5)$ & Missing & $141(0.7)$ & Missing \\
\hline Don't know & $355(1.7)$ & Missing & $164(0.8)$ & Missing \\
\hline Don't want to answer & $22(0.1)$ & Missing & $18(0.1)$ & Missing \\
\hline \multicolumn{5}{|c|}{ Independent variables: Recognition of symptoms as cancer symptoms } \\
\hline & \multicolumn{2}{|c|}{$\begin{array}{l}\text { Do you think persistent cough or hoarseness } \\
\text { could be a warning sign for cancer? }\end{array}$} & \multicolumn{2}{|c|}{$\begin{array}{l}\text { Do you think unexplained bleeding could be a warning } \\
\text { sign for cancer? }\end{array}$} \\
\hline Response categories: & N (\%) & Classification & N (\%) & Classification \\
\hline Yes & $15,155(72.8)$ & Recognition & $18,187(87.4)$ & Recognition \\
\hline No & $4951(23.8)$ & Non-recognition & $2018(9.7)$ & Non-recognition \\
\hline Don't know & $693(3.3)$ & Missing & $598(2.9)$ & Missing \\
\hline Don't want to answer & $15(7.2)$ & Missing & $11(0.0)$ & Missing \\
\hline \multicolumn{5}{|c|}{ Independent variable/moderator: Negative cancer beliefs (NCBs) } \\
\hline \multicolumn{5}{|c|}{ Answers classified as NCBs are highlighted in bold. } \\
\hline \multicolumn{5}{|c|}{ The answers "don't know" and "don't want to answer" were classified as missing. } \\
\hline & \multicolumn{2}{|c|}{ Strongly disagree or tend to disagree } & Strongly agree or tend to agree & Don't know or refused \\
\hline & \multicolumn{2}{|l|}{ N (\%) } & N (\%) & N (\%) \\
\hline $\begin{array}{l}\text { People with cancer can expect to } \\
\text { continue with normal activities }\end{array}$ & \multicolumn{2}{|l|}{$1936(9.3)$} & $18,187(87.4)$ & $691(3.3)$ \\
\hline Cancer can often be cured & \multicolumn{2}{|l|}{$1853(8.9)$} & $18,502(88.9)$ & $459(2.2)$ \\
\hline $\begin{array}{l}\text { Going to the doctor as quickly as } \\
\text { possible after noticing a symptom } \\
\text { of cancer could increase the } \\
\text { chances of surviving }\end{array}$ & \multicolumn{2}{|l|}{$394(1.9)$} & 20,310 (97.6) & $110(0.5)$ \\
\hline $\begin{array}{l}\text { Cancer treatment is worse than the } \\
\text { cancer itself }\end{array}$ & \multicolumn{2}{|l|}{7196 (34.6) } & $11,082(53.2)$ & $2536(12.2)$ \\
\hline I would not want to know if I have cancer & \multicolumn{2}{|l|}{$18,004(86.5)$} & $2337(11.2)$ & $473(2.3)$ \\
\hline A diagnosis of cancer is a death sentence & \multicolumn{2}{|l|}{$14,995(72.0)$} & $5110(24.6)$ & 709 (3.4) \\
\hline
\end{tabular}

$\mathrm{HCP}=$ Healthcare professional; $\mathrm{pt} .=$ patient

number of $\mathrm{NCBs}\left(\mathrm{OR}_{\geq} 4 \mathrm{NCBs}=1.97,95 \% \mathrm{CI}=1.51-\right.$ 2.57) were independently associated with an increased likelihood of a longer anticipated patient interval for rectal bleeding (Table 4). In both models, there was a dose-response relationship between the number of NCBs and the likelihood of a longer anticipated patient interval.
The results of the sensitivity analysis (the answer "don't know" coded as "non-recognition" of symptom instead of missing) confirmed a statistically independent influence of non-recognition of symptoms $\left(\mathrm{OR}_{\text {persistent }}\right.$ cough $=1.57,95 \% \mathrm{CI}=1.40-1.77 ; \mathrm{OR}_{\text {rectal bleeding }}=1.70$, 95\% CI $=1.43-2.01)$ and number of NCBs $\left(\mathrm{OR}_{\text {persistent }}\right.$ cough $=2.27,95 \% \mathrm{CI}=1.79-2.89 ; \mathrm{OR}_{\text {rectal bleeding }}=1.98$, 
Table 2 Description of the sample

\begin{tabular}{|c|c|c|c|}
\hline & All & Females & Males \\
\hline & $N=20,814(100 \%)$ & $N=12,456(59.8 \%)$ & $N=8358(40.2 \%)$ \\
\hline \multicolumn{4}{|l|}{ Age group, n (\%) } \\
\hline $50-59$ years & 7375 (35.4) & $4414(35.4)$ & $2961(35.4)$ \\
\hline $60-69$ years & $7510(36.1)$ & $4416(35.5)$ & 3094 (37.0) \\
\hline 70-79 years & $4234(20.3)$ & 2564 (20.6) & $1670(20.0)$ \\
\hline$\geq 80$ years & $1695(8.1)$ & $1062(8.5)$ & $633(7.6)$ \\
\hline \multicolumn{4}{|l|}{ Marital status } \\
\hline Cohabiting & $12,665(60.9)$ & $6747(54.2)$ & $5918(70.8)$ \\
\hline Single & 8082 (38.8) & $5665(45.5)$ & $2417(28.9)$ \\
\hline \multicolumn{4}{|l|}{ Education } \\
\hline No university degree & $14,334(68.9)$ & 8911 (71.5) & $5423(64.9)$ \\
\hline University degree & $6331(30.4)$ & $3448(27.7)$ & $2883(34.5)$ \\
\hline \multicolumn{4}{|l|}{ Smoking status } \\
\hline Not current smoker & $17,600(84.6)$ & $10,605(85.1)$ & $6995(83.7)$ \\
\hline Current smoker & 3207 (15.4) & $1847(14.8)$ & $1360(16.3)$ \\
\hline \multicolumn{4}{|c|}{ Experience of cancer (self and/or family/friend) } \\
\hline Yes & $17,157(82.4)$ & $10,698(85.9)$ & $6459(77.3)$ \\
\hline No & $3629(17.4)$ & $1745(14.0)$ & $1884(22.5)$ \\
\hline \multicolumn{4}{|c|}{ Anticipated interval for persistent cough } \\
\hline Short & $16,006(76.9)$ & $9578(76.9)$ & $6428(76.9)$ \\
\hline Long (> 1 month) & $4111(19.8)$ & $2466(19.8)$ & $1645(19.7)$ \\
\hline \multicolumn{4}{|c|}{ Anticipated interval for rectal bleeding } \\
\hline Short & $17,634(84.7)$ & $10,588(85.0)$ & $7046(84.3)$ \\
\hline Long (> 1 week) & $2857(13.7)$ & $1675(13.5)$ & $1182(14.1)$ \\
\hline \multicolumn{4}{|c|}{ Recognition of persistent cough or hoarseness as cancer symptom } \\
\hline Yes & $15,155(72.8)$ & $9501(76.3)$ & $5654(67.7)$ \\
\hline No & $4951(23.8)$ & $2558(20.5)$ & $2393(28.6)$ \\
\hline \multicolumn{4}{|c|}{ Recognition of unexplained bleeding as cancer symptom } \\
\hline Yes & $18,187(87.4)$ & $11,157(89.6)$ & $7030(84.1)$ \\
\hline No & $2018(9.7)$ & $1005(8.1)$ & $1013(12.1)$ \\
\hline \multicolumn{4}{|c|}{ Number of negative cancer beliefs (coded as) } \\
\hline $0(0)$ & $6427(30.9)$ & $3420(27.5)$ & $3007(36.0)$ \\
\hline $1(1)$ & $8412(40.4)$ & $5225(42.0)$ & $3187(38.1)$ \\
\hline $2(2)$ & $4180(20.1)$ & $2682(21.5)$ & $1498(17.9)$ \\
\hline $3(3)$ & $1347(6.5)$ & $849(6.8)$ & $498(6.0)$ \\
\hline $4-6(>4)$ & $448(2.2)$ & $280(2.3)$ & $168(2.0)$ \\
\hline
\end{tabular}

Sums vary because of missing data

95\% CI $=1.53-2.58)$ on the likelihood of a long anticipated patient interval for persistent cough and rectal bleeding (adjusted analyses, data not shown).

No statistically significant interaction effect of NCBs and not recognising cough or hoarseness on the likelihood of a long anticipated patient interval for persistent cough was revealed in the moderation analysis (Table 3 ). However, the moderation analysis revealed a significant interaction of $\mathrm{NCBs}$ with non-recognition of unexplained bleeding on the likelihood of a long anticipated patient interval for rectal bleeding, and the likelihoodratio test confirmed that the statistical model with the interaction term was significantly different from the model without the interaction term $\left(\mathrm{LR} \mathrm{chi}^{2}=7.97, p=\right.$ 0.005; Table 4). In Fig. 2, the predicted probabilities of reporting a long anticipated patient interval for rectal 
Table 3 Associations between recognition of persistent cough or hoarseness as cancer symptom, negative beliefs about cancer and long anticipated patient interval for persistent cough $\left(\mathrm{n}_{\text {adjusted }}=19,277\right)$

\begin{tabular}{|c|c|c|c|c|c|c|c|}
\hline & \multicolumn{4}{|l|}{ Unadjusted } & \multicolumn{3}{|c|}{ Adjusted* } \\
\hline & \multicolumn{4}{|c|}{$\begin{array}{l}\text { Outcome: long anticipated patient } \\
\text { interval for cough ( }>1 \text { month) }\end{array}$} & \multicolumn{3}{|c|}{$\begin{array}{l}\text { Outcome: long } \\
\text { anticipated patient } \\
\text { interval for cough } \\
\text { (> } 1 \text { month) }\end{array}$} \\
\hline & $\begin{array}{l}\text { Proportion with } \\
\text { long interval (\%) }\end{array}$ & OR & $95 \% \mathrm{Cl}$ & $P$-value & $\mathrm{OR}$ & $95 \% \mathrm{Cl}$ & $P$-value \\
\hline \multicolumn{8}{|l|}{ Recognition of persistent cough or hoarseness as cancer symptom } \\
\hline Yes & 18.5 & Ref. & & & Ref. & & \\
\hline No & 26.7 & 1.60 & $1.49-1.73$ & $<0.001$ & 1.66 & $1.47-1.87$ & $<0.001$ \\
\hline \multicolumn{8}{|l|}{ Number of negative beliefs about cancer } \\
\hline 0 & 19.8 & Ref. & & & Ref. & & \\
\hline 1 & 19.3 & 0.97 & $0.89-1.05$ & 0.453 & 0.97 & $0.89-1.06$ & 0.522 \\
\hline 2 & 20.7 & 1.05 & $0.95-1.16$ & 0.312 & 1.06 & $0.95-1.19$ & 0.305 \\
\hline 3 & 24.5 & 1.31 & $1.14-1.51$ & $<0.001$ & 1.33 & $1.13-1.57$ & 0.001 \\
\hline$\geq 4$ & 36.3 & 2.31 & $1.87-2.84$ & $<0.001$ & 2.18 & $1.71-2.78$ & $<0.001$ \\
\hline \multicolumn{8}{|l|}{ Age group } \\
\hline $50-59$ years & 23.1 & Ref. & & & Ref. & & \\
\hline $60-69$ years & 21.3 & 0.90 & $0.84-0.98$ & 0.012 & 0.93 & $0.86-1.01$ & 0.087 \\
\hline 70-79 years & 17.0 & 0.68 & $0.62-0.76$ & $<0.001$ & 0.75 & $0.67-0.83$ & $<0.001$ \\
\hline$\geq 80$ years & 13.1 & 0.50 & $0.43-0.59$ & $<0.001$ & 0.57 & $0.48-0.67$ & $<0.001$ \\
\hline \multicolumn{8}{|l|}{ Sex } \\
\hline Female & 20.5 & Ref. & & & Ref. & & \\
\hline Male & 20.4 & 0.99 & $0.93-1.07$ & 0.865 & 0.93 & $0.86-1.00$ & 0.042 \\
\hline \multicolumn{8}{|l|}{ Marital status } \\
\hline Cohabiting & 21.1 & Ref. & & & Ref. & & \\
\hline Single & 19.3 & 0.89 & $0.83-0.96$ & 0.002 & 0.93 & $0.86-1.00$ & 0.057 \\
\hline \multicolumn{8}{|l|}{ Education } \\
\hline No university degree & 19.6 & Ref. & & & Ref. & & \\
\hline University degree & 22.3 & 1.18 & $1.09-1.27$ & $<0.001$ & 1.24 & $1.15-1.34$ & $<0.001$ \\
\hline \multicolumn{8}{|l|}{ Smoking status } \\
\hline Not current smoker & 19.4 & Ref. & & & Ref. & & \\
\hline Current smoker & 26.1 & 1.47 & $1.34-1.60$ & $<0.001$ & 1.38 & $1.26-1.52$ & $<0.001$ \\
\hline \multicolumn{8}{|l|}{ Experience of cancer (self and/or family/friend) } \\
\hline Yes & 20.7 & Ref. & & & Ref. & & \\
\hline No & 19.0 & 0.90 & $0.82-0.98$ & 0.020 & 0.85 & $0.77-0.93$ & 0.001 \\
\hline \multicolumn{8}{|l|}{ Country } \\
\hline UK & 22.5 & Ref. & & & Ref. & & \\
\hline Australia & 16.9 & 0.70 & $0.63-0.77$ & $<0.001$ & 0.70 & $0.63-0.78$ & $<0.001$ \\
\hline Canada & 18.8 & 0.79 & $0.72-0.88$ & $<0.001$ & 0.74 & $0.67-0.83$ & $<0.001$ \\
\hline Denmark & 21.3 & 0.93 & $0.82-1.05$ & 0.229 & 0.88 & $0.78-1.00$ & 0.053 \\
\hline Norway & 24.9 & 1.14 & $1.01-1.28$ & 0.031 & 1.10 & $0.97-1.24$ & 0.137 \\
\hline Sweden & 18.2 & 0.77 & $0.67-0.87$ & $<0.001$ & 0.72 & $0.64-0.83$ & $<0.001$ \\
\hline \multicolumn{8}{|l|}{ Test of moderation } \\
\hline Negative beliefs $x$ Non-recognition of persistent cough or hoarseness & & & & & 0.99 & $0.92-1.07$ & 0.831 \\
\hline
\end{tabular}


Table 3 Associations between recognition of persistent cough or hoarseness as cancer symptom, negative beliefs about cancer and long anticipated patient interval for persistent cough ( $n_{\text {adjusted }}=19,277$ ) (Continued)

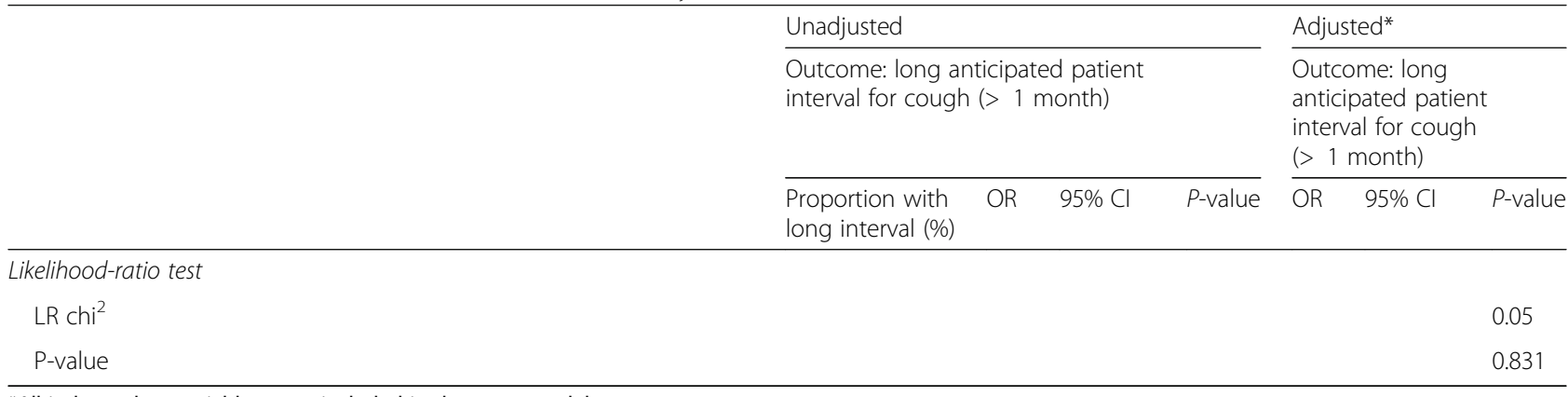

${ }^{*}$ All independent variables were included in the same model

bleeding across different levels of NCBs are depicted. The predicted probability of a long anticipated patient interval for those who recognised unexplained bleeding as a possible cancer symptom increased with number of NCBs. For those reporting four or more NCBs, the predicted probability of a long anticipated patient interval for rectal bleeding was the same regardless of whether they recognised unexplained bleeding as a cancer symptom or not. For those who did not recognise unexplained bleeding as a cancer symptom, the predicted probabilities for a long anticipated patient interval for rectal bleeding decreased with increasing number of NCBs.

\section{Discussion}

\section{Main findings}

Not recognising persistent cough/hoarseness and unexplained bleeding as possible signs of cancer and number of NCBs were independently associated with an increased likelihood of longer anticipated patient intervals for persistent cough and rectal bleeding, respectively. There was a dose-response relationship between number of NCBs and longer anticipated patient intervals for persistent cough and rectal bleeding. Hence, a high level of NCBs may act as a barrier to help-seeking when experiencing a symptom that could be a sign of cancer. Furthermore, we found that number of NCBs was an effect moderator as when respondents reported four or more NCBs, the risk of a long anticipated patient interval for rectal bleeding would be the same whether the respondent had recognised unexplained bleeding as a cancer symptom or not. Number of NCBs could only be documented as an effect moderator in the model of bleeding and not in the model of cough. Respondents estimated that they would wait longer before seeking help for a persisting cough than for rectal bleeding and in line with this finding, respondents in another survey seldom recognised cough or hoarseness as a cancer symptom [14]. If respondents do not see persistent cough as a "red flag" symptom in the same way they see rectal bleeding, it seems plausible that the role of NCBs may be different in the two models. The moderating potential of NCBs may only come into play when the symptom is experienced as serious and the symptom recognition thereby causes anxiety [15].

We find it difficult to explain why the probability of a long anticipated patient interval for rectal bleeding decreased with increasing number of NCBs among those who did not recognise unexplained bleeding as a cancer symptom. The number of respondents who did not recognise unexplained bleeding as a cancer symptom was relatively small compared to those who did and therefore, when subdividing the group based on number of NCBs, the confidence intervals became rather wide as was evident in Fig. 2 and results from this analysis should be interpreted with caution.

\section{Strengths and limitations}

Among the strengths of this study was the use of a population-representative sample and that we used an internationally validated questionnaire for assessing recognition of cancer symptoms and NCBs outcomes [12]. A potential weakness is that the anticipated help-seeking interval was hypothetical and might not mirror the response if a person experienced the symptom in reality. The majority of respondents (61\%) reported that they would seek help immediately if they experienced rectal bleeding, but a review of 38 studies examining patient intervals in colorectal cancer showed that the actual median patient interval ranged from 7 days to 5 months [16]. This suggests that at least some of the participants in our study have underestimated how long they would actually wait before seeking help. Further, since the present data were cross-sectional, the causality of associations cannot be determined.

\section{Comparisons with existing literature}

Several other studies have found that lack of knowledge of cancer symptoms is associated with longer anticipated patient intervals [5] and actual patient intervals [2-4]. 
Table 4 Associations between recognition of unexplained bleeding as cancer symptom, negative beliefs about cancer and long anticipated patient interval for rectal bleeding $\left(n_{\text {adjusted }}=19,695\right)$

\begin{tabular}{|c|c|c|c|c|c|c|c|}
\hline & \multicolumn{4}{|l|}{ Unadjusted } & \multicolumn{3}{|c|}{ Adjusted* } \\
\hline & \multicolumn{4}{|l|}{$\begin{array}{l}\text { Outcome: long anticipated } \\
\text { patient interval for rectal } \\
\text { bleeding (> } 1 \text { week) }\end{array}$} & \multicolumn{3}{|c|}{$\begin{array}{l}\text { Outcome: long anticipated } \\
\text { patient interval for rectal } \\
\text { bleeding ( }>1 \text { week) }\end{array}$} \\
\hline & Proportion with long interval (\%) & OR & $95 \% \mathrm{Cl}$ & $P$-value & $\overline{\mathrm{OR}}$ & $95 \% \mathrm{Cl}$ & $P$-value \\
\hline \multicolumn{8}{|c|}{ Recognition of unexplained bleeding as cancer symptom } \\
\hline Yes & 13.3 & Ref. & & & Ref. & & \\
\hline No & 19.7 & 1.59 & $1.41-1.79$ & $<0.001$ & 1.90 & $1.58-2.30$ & $<0.001$ \\
\hline \multicolumn{8}{|c|}{ Number of negative beliefs about cancer } \\
\hline 0 & 13.0 & Ref. & & & Ref. & & \\
\hline 1 & 13.8 & 1.07 & $0.98-1.18$ & 0.147 & 1.11 & $1.00-1.22$ & 0.051 \\
\hline 2 & 14.4 & 1.13 & $1.01-1.27$ & 0.034 & 1.21 & $1.07-1.37$ & 0.002 \\
\hline 3 & 15.8 & 1.26 & $1.06-1.48$ & 0.007 & 1.41 & $1.18-1.69$ & $<0.001$ \\
\hline$\geq 4$ & 20.3 & 1.71 & $1.34-2.18$ & $<0.001$ & 1.97 & $1.51-2.57$ & $<0.001$ \\
\hline \multicolumn{8}{|l|}{ Age group } \\
\hline 50-59 years & 16.6 & Ref. & & & Ref. & & \\
\hline $60-69$ years & 14.0 & 0.82 & $0.75-0.90$ & $<0.001$ & 0.82 & $0.75-0.90$ & $<0.001$ \\
\hline 70-79 years & 11.4 & 0.65 & $0.58-0.73$ & $<0.001$ & 0.67 & $0.59-0.76$ & $<0.001$ \\
\hline$\geq 80$ years & 8.5 & 0.46 & $0.39-0.56$ & $<0.001$ & 0.51 & $0.41-0.62$ & $<0.001$ \\
\hline \multicolumn{8}{|l|}{ Sex } \\
\hline Female & 13.7 & Ref. & & & Ref. & & \\
\hline Male & 14.4 & 1.06 & $0.98-1.15$ & 0.152 & 1.03 & $0.95-1.12$ & 0.495 \\
\hline \multicolumn{8}{|l|}{ Marital status } \\
\hline Cohabiting & 14.3 & Ref. & & & Ref. & & \\
\hline Single & 13.5 & 0.93 & $0.86-1.01$ & 0.103 & 1.08 & $0.99-1.18$ & 0.086 \\
\hline \multicolumn{8}{|l|}{ Education } \\
\hline No university degree & 12.9 & Ref. & & & Ref. & & \\
\hline University degree & 16.4 & 1.33 & $1.22-1.44$ & $<0.001$ & 1.29 & $1.18-1.41$ & $<0.001$ \\
\hline \multicolumn{8}{|l|}{ Smoking status } \\
\hline Not current smoker & 14.0 & Ref. & & & Ref. & & \\
\hline Current smoker & 13.9 & 1.00 & $0.90-1.12$ & 0.990 & 0.91 & $0.81-1.02$ & 0.111 \\
\hline \multicolumn{8}{|c|}{ Experience of cancer (self and/or family/friend) } \\
\hline Yes & 14.2 & Ref. & & & Ref. & & \\
\hline No & 12.6 & 0.87 & $0.78-0.97$ & 0.010 & 0.85 & $0.76-0.95$ & 0.006 \\
\hline \multicolumn{8}{|l|}{ Country } \\
\hline UK & 13.6 & Ref. & & & Ref. & & \\
\hline Australia & 8.6 & 0.59 & $0.52-0.68$ & $<0.001$ & 0.60 & $0.52-0.68$ & $<0.001$ \\
\hline Canada & 15.1 & 1.13 & $1.01-1.27$ & 0.033 & 1.04 & $0.93-1.17$ & 0.480 \\
\hline Denmark & 14.6 & 1.08 & $0.94-1.25$ & 0.270 & 1.00 & $0.86-1.16$ & 0.990 \\
\hline Norway & 19.4 & 1.52 & $1.34-1.74$ & $<0.001$ & 1.46 & $1.27-1.68$ & $<0.001$ \\
\hline Sweden & 17.1 & 1.31 & $1.14-1.50$ & $<0.001$ & 1.22 & $1.06-1.41$ & 0.005 \\
\hline \multicolumn{8}{|l|}{ Test of moderation } \\
\hline $\begin{array}{l}\text { Negative beliefs } x \text { Non-recognition } \\
\text { of unexplained bleeding }\end{array}$ & & & & & 0.84 & $0.75-0.95$ & 0.005 \\
\hline \multicolumn{8}{|l|}{ Likelihood-ratio test } \\
\hline LR chi ${ }^{2}$ & & & & & & & 7.97 \\
\hline P-value & & & & & & & 0.005 \\
\hline
\end{tabular}

*All independent variables were included in the same model 


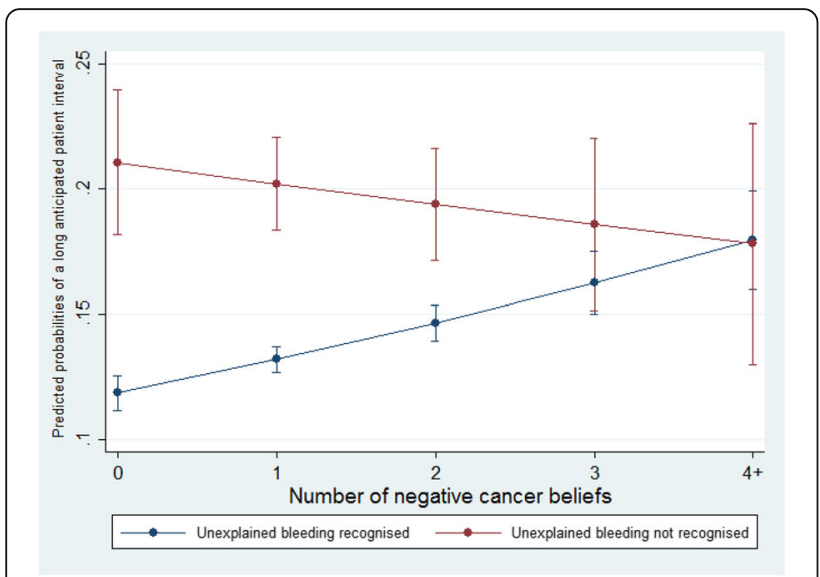

Fig. 2 Predicted probabilities of a long anticipated patient interval with 95\% Cls for respondents who recognised or did not recognise unexplained bleeding as cancer symptom and with various levels of negative cancer beliefs

The influence of NCBs on length of the patient interval has been less frequently studied. Qualitative studies have found that negative expectations of the health care professional make patients with potentially malignant oral symptoms more likely to postpone help-seeking [17], that older women ( $\geq 65$ years) were deterred from seeking help because of negative expectations to surgical and medical treatments [18] and that poor confidence in the healthcare system was a reason for not seeking help when experiencing cancer alarm symptoms [19]. Further, a review of 32 qualitative studies revealed that a fatalistic attitude to cancer was one of the main reasons for delaying help-seeking as well as interpreting symptoms as benign and self-limiting [20].

The Extended Parallel Process Model (EPPM) [21, 22] may be useful for explaining the moderating effect of $\mathrm{NCBs}$ on the increased likelihood of longer anticipated patient intervals for potential colorectal symptoms. Thus, recognition of a symptom as a possible sign of cancer may give rise to fear, which has been identified as a barrier to help-seeking as well as a factor which could promote prompt help-seeking for cancer symptoms [19, 23]. According to the EPPM, fear will induce protective danger control processes (e.g. fast help-seeking) only if the individual believes that $\mathrm{s} / \mathrm{he}$ is able to deal with the threat [21, 24]. If NCBs about the disease and its treatment are salient and the individual believes that no action will be effective dealing with the disease, the fear will induce fear control processes such as denial and downplay of worrisome symptoms, meaning that helpseeking may be postponed.

\section{Conclusion}

It is often assumed that patients with sufficient knowledge about possible cancer symptoms would engage in appropriate help-seeking [6]. The results of the present study support this notion, as people who recognised cancer symptoms reported shorter anticipated patient intervals compared to people who did not recognise these symptoms as possible signs of cancer. Meanwhile, a high number of NCBs also increased the likelihood of long anticipated patient intervals, and the association between recognition of unexplained bleeding as a cancer symptom and the intention to seek help quickly for rectal bleeding was only seen in respondents who reported few NCBs. Therefore, it is equally important that NCBs are addressed in interventions designed to shorten patient intervals.

\section{Additional file}

Additional file 1: Description of sample countrywise. (DOC 81 kb)

\section{Abbreviations}

ABC: Awareness and beliefs about cancer Measure; Cl: Confidence interval; EPPM: Extended Parallel Process Model; ICBP: International cancer benchmarking partnership; NCB: Negative cancer belief

\section{Acknowledgements}

We express our respect and admiration of Professor Jane Wardle who sadly died October 20 2015, but who supported this study and left a major imprint on the ICBP Module 2 working group with her pioneering research. We thank Anders Helles Carlsen for his thorough statistical guidance. The authors thank Anna Carluccio, Colin Gardiner, Julia Pye, Laura Thomas and Chris Marshall of IPSOS Mori for coordinating the fieldwork, and Kate Aldersey, Martine Bomb, Catherine Foot, Donia Sadik and Emily Fulleylove of Cancer Research UK for managing the programme (at the time of the study) and monitoring the media.

ICBP Programme Board (at the time of the study): Ole Andersen, Søren Brostrøm, Heather Bryant, David Currow, Anna Gavin, Gunilla Gunnarsson, Jane Hanson, Todd Harper, Stein Kaasa, Nicola Quin, Linda Rabeneck, Michael A Richards, Michael Sherar and Bob Thomas.

Academic Reference Group: Neil Aaronson, David Cella, Henrik Møller, Keith Petrie and Liesbeth Van Osch. ICBP Module 2 Working Group: Jane Wardle, Michael Donnelly, David Donnelly, Deb Keen, Chris Roberts, James Kite, Blythe O'Hara, Donna Perez, Lisa Petermann, Christian Wulff, Kate Brain and Melanie Wakefield.

\section{Funding}

Australia: Cancer Council Victoria, Department of Health Victoria, Cancer Institute New South Wales; Canada: Canadian Partnership against Cancer: Denmark: Danish Cancer Society and Novo Nordic Foundation; Norway: Norwegian Directorate for Health and Social Affairs; Sweden: Swedish Social Ministry and the Association of Local Authorities and Regions; United Kingdom: Department of Health/National Cancer Action Team, Northern Ireland Public Health Agency, Tenovus and Welsh Government. The funders were not involved in study design, collection, analysis and interpretation of the data, writing of the article or the decision to submit it for publication. Where the author was employed by the funding organisation, the governing body of the organisation had no influence on any of these.

\section{Availability of data and materials}

No additional datasets are available.

\section{Authors' contributions}

Study concepts: AFP, LF, KB and PV. Study design: AFP, LF, KB, LH and PV. Data acquisition: AFP, LF, KB, LH, CNW, ML and PV. Data analysis and interpretation: AFP, LF, KB, LH, CNW, ML, SH, SLQ and PV. Statistical analysis and manuscript preparation: AFP and PV. All authors contributed to the editing of the manuscript and read and approved the final manuscript. 


\section{Ethics approval and consent to participate}

The study was conducted in accordance with ethical guidelines in each participating jurisdiction. Commonly, no ethical approval was required, since the study was based on survey data. Wherever appropriate, reference numbers are stated: Australia: New South Wales Population and Health Services Research Ethics Committee, Anti-Cancer Council of Victoria's Human Research Ethics Committee (\#0018); Canada: Conjoint Health Research Ethics Board of the University of Calgary (E-23667); Denmark: Danish Data Protection Agency (2011-41-6237); Norway: Norway Social Science Data Services (\#27427); Sweden: Regionale etikprövningsämnden i Stockholm (2011/ 699-31/2); UK: University College London Research Ethics Committee for the Queen's University School of Medicine, Dentistry, and Biomedical Science, Cardiff University School of Medicine (1122/003). Written informed consent was not obtained from the participants as the interviews could not be performed with permission from the interviewees.

\section{Consent for publication}

Not applicable.

\section{Competing interests}

The authors declare that they have no competing interests.

\section{Publisher's Note}

Springer Nature remains neutral with regard to jurisdictional claims in published maps and institutional affiliations.

\section{Author details}

${ }^{1}$ Research Unit for General Practice and Research Centre for Cancer Diagnosis in Primary Care (CaP), Aarhus University, Bartholins Allé 2, 8000 Aarhus C, Denmark. ${ }^{2}$ King's College London Promoting Early Cancer Presentation Group, Capital House, 42 Weston Street, London SE1 3QD, UK. ${ }^{3}$ Cochrane Institute of Primary Care and Public Health, Neuadd Meirionydd, School of Medicine, Cardiff University, Heath Park, Cardiff CF14 4YS, UK. ${ }^{4}$ Department of Oncology, Aarhus University Hospital, Norrebrogade 44, 8000 Aarhus C, Denmark. ${ }^{5}$ Department of Learning, Informatics, Management and Ethics (LIME), Karolinska Institutet, Tomtebodavägen 18A, Stockholm, Sweden. ${ }^{6}$ Department of Nursing, Umeå University, SE-901 87 Umeå, Sweden. ${ }^{7}$ Health Behaviour Research Centre, Department of Epidemiology and Public Health, University College London, Gower Street, WC1E 6BT, London, UK.

Received: 15 March 2016 Accepted: 21 March 2018

Published online: 02 April 2018

\section{References}

1. Weller D, Vedsted P, Rubin G, Walter FM, Emery J, Scott S, Campbell C, Andersen RS, Hamilton W, Olesen F, Rose P, Nafees S, van Rijswijk E, Hiom S, Muth C, Beyer M, Neal RD. The Aarhus statement: improving design and reporting of studies on early cancer diagnosis. Br J Cancer. 2012;106(7): $1262-7$

2. Forbes $L J$, Warburton F, Richards MA, Ramirez AJ. Risk factors for delay in symptomatic presentation: a survey of cancer patients. Br J Cancer. 2014; 111(3):581-8.

3. Macleod U, Mitchell ED, Burgess C, Macdonald S, Ramirez AJ. Risk factors for delayed presentation and referral of symptomatic cancer: evidence for common cancers. Br J Cancer. 2009;101 (Suppl 2):S92-S101.

4. Simon AE, Waller J, Robb K, Wardle J. Patient delay in presentation of possible cancer symptoms: the contribution of knowledge and attitudes in a population sample from the United Kingdom. Cancer Epidemiol Biomark Prev. 2010;19(9):2272-7.

5. Quaife SL, Forbes LJ, Ramirez AJ, Brain KE, Donnelly C, Simon AE, Wardle J. Recognition of cancer warning signs and anticipated delay in help-seeking in a population sample of adults in the UK. Br J Cancer. 2014;110(1):12-8.

6. Sheikh I, Ogden J. The role of knowledge and beliefs in help seeking behaviour for cancer: a quantitative and qualitative approach. Patient Educ Couns. 1998;35(1):35-42.

7. Andersen RS, Vedsted P, Olesen F, Bro F, Sondergaard J. Does the organizational structure of health care systems influence care-seeking decisions? A qualitative analysis of Danish cancer patients' reflections on care-seeking. Scand J Prim Health Care. 2011;29(3):144-9.
8. Butler J, Foot C, Bomb M, Hiom S, Coleman M, Bryant H, Vedsted P, Hanson J, Richards M. ICBP working group: the international Cancer benchmarking partnership: an international collaboration to inform cancer policy in Australia, Canada, Denmark, Norway, Sweden and the United Kingdom. Health Policy. 2013;112(1-2):148-55.

9. Forbes LJ, Simon AE, Warburton F, Boniface D, Brain KE, Dessaix A, Donnelly C, Haynes K, Hvidberg L, Lagerlund M, Lockwood G, Tishelman C, Vedsted P, Vigmostad MN, Ramirez AJ, Wardle J. International Cancer benchmarking partnership module 2 working group: differences in cancer awareness and beliefs between Australia, Canada, Denmark, Norway, Sweden and the UK (the international Cancer benchmarking partnership): do they contribute to differences in cancer survival? Br J Cancer. 2013;108(2):292-300.

10. Hvidberg L, Wulff CN, Pedersen AF, Vedsted P. Barriers to healthcare seeking, beliefs about cancer and the role of socio-economic position. A Danish population-based study. Prev Med. 2015;71:107-13.

11. Forbes $L L L$, Simon AE, Warburton F, Boniface D, Brain KE, Dessaix A, Donnelly C, Haynes K, Hvidberg L, Lagerlund M, Lockwood G, Tishelman C, Vedsted P, Vigmostad MN, Ramirez AJ, Wardle J. Differences in cancer awareness and beliefs between Australia, Canada, Denmark, Norway, Sweden and the UK (the international Cancer benchmarking partnership): do they contribute to differences in cancer survivalquest. Br J Cancer. 2014;111(12):2382.

12. Simon $A E$, Forbes $L$, Boniface $D$, Warburton $F$, Brain $K E$, Dessaix $A$, Donnelly M, Haynes K, Hvidberg L, Lagerlund M, Petermann L, Tishelman C, Vedsted P, Vigmostad MN, Wardle J, Ramirez AJ, ICBP Module 2 Working Group, ICBP Programme Board and Academic Reference Group. An international measure of awareness and beliefs about cancer: development and testing of the ABC. BMJ Open. 2012;2(6) https://doi.org/10.1136/bmjopen-2012001758. Print 2012

13. Quaife SL, McEwen A, Janes SM, Wardle J. Smoking is associated with pessimistic and avoidant beliefs about cancer: results from the international Cancer benchmarking partnership. Br J Cancer. 2015;1 12(11):1799-804.

14. Niksic M, Rachet B, Warburton FG, Wardle J, Ramirez AJ, Forbes LJ. Cancer symptom awareness and barriers to symptomatic presentation in Englandare we clear on cancer? Br J Cancer. 2015;113(3):533-42.

15. Hajdarevic S, Hörnsten Å, Sundbom E, Brulin C, Schmitt-Egenolf M. Patients' decision making in seeking care for suspected malignant melanoma. Journal of Nursing and Healthcare of Chronic Illness. 2010;2:164-73.

16. Mitchell E, Macdonald S, Campbell NC, Weller D, Macleod U. Influences on pre-hospital delay in the diagnosis of colorectal cancer: a systematic review. Br J Cancer. 2008;98(1):60-70.

17. Scott SE, Grunfeld EA, Auyeung V, McGurk M. Barriers and triggers to seeking help for potentially malignant oral symptoms: implications for interventions. J Public Health Dent. 2009;69(1):34-40.

18. Burgess CC, Potts HW, Hamed H, Bish AM, Hunter MS, Richards MA, Ramirez AJ. Why do older women delay presentation with breast cancer symptoms? Psychooncology. 2006;15(11):962-8.

19. Whitaker KL, Macleod U, Winstanley K, Scott SE, Wardle J. Help seeking for cancer 'alarm' symptoms: a qualitative interview study of primary care patients in the UK. Br J Gen Pract. 2015;65(631):e96-e105.

20. Smith LK, Pope C, Botha JL. Patients' help-seeking experiences and delay in cancer presentation: a qualitative synthesis. Lancet. 2005;366(9488):825-31.

21. Witte K. Putting the fear back into fear appeals: the extended parallel process model. Commun Monogr. 1992;59:329-49.

22. Witte $\mathrm{K}$, Allen M. A meta-analysis of fear appeals: implications for effective public health campaigns. Health Educ Behav. 2000;27(5):591-615.

23. Balasooriya-Smeekens C, Walter FM, Scott S. The role of emotions in time to presentation for symptoms suggestive of cancer: a systematic literature review of quantitative studies. Psychooncology. 2015;24(12):1594-604.

24. Ruiter RA, Kessels LT, Peters GJ, Kok G. Sixty years of fear appeal research: current state of the evidence. Int J Psychol. 2014;49(2):63-70. 